\title{
Association between ventilatory settings and development of acute respiratory distress syndrome in mechanically ventilated patients due to brain injury 2 s
}

\author{
Eva Tejerina a,*, Paolo Pelosi ${ }^{\mathrm{b}}$, Alfonso Muriel ${ }^{\mathrm{c}}$, Oscar Peñuelas ${ }^{\mathrm{a}}$, Yuda Sutherasan ${ }^{\mathrm{d}}$, Fernando Frutos-Vivar ${ }^{\mathrm{a}}$, \\ Nicolás Nin ${ }^{\mathrm{e}}$, Andrew R. Davies ${ }^{\mathrm{f}}$, Fernando Rios ${ }^{\mathrm{g}}$, Damian A. Violi ${ }^{\mathrm{h}}$, Konstantinos Raymondos ${ }^{\mathrm{i}}$, Javier Hurtado ${ }^{\mathrm{j}}$, \\ Marco González ${ }^{\mathrm{k}}$, Bin Du ${ }^{\mathrm{l}}$, Pravin Amin ${ }^{\mathrm{m}}$, Salvatore M. Maggiore ${ }^{\mathrm{n}}$, Arnaud W. Thille ${ }^{\mathrm{o}}$, Marco Antonio Soares ${ }^{\mathrm{p}}$, \\ Manuel Jibaja ${ }^{\mathrm{q}}$, Asisclo J. Villagomez ${ }^{\mathrm{r}}$, Michael A. Kuiper ${ }^{\mathrm{s}}$, Younsuck Koh ${ }^{\mathrm{t}}$, Rui P. Moreno ${ }^{\mathrm{u}}$, \\ Amine Ali Zeggwagh v , Dimitrios Matamis ${ }^{w}$, Antonio Anzueto ${ }^{\mathrm{x}, 1}$, Niall D. Ferguson ${ }^{\mathrm{y}, 1}$, Andrés Esteban ${ }^{\mathrm{a}, 1}$, \\ for VENTILA group
}

${ }^{a}$ Hospital Universitario de Getafe E' Centro de Investigación Biomédica en Red de Enfermedades Respiratorias (CIBERES), Spain

${ }^{\mathrm{b}}$ Department of Surgical Sciences and Integrated Diagnostics, IRCCS AOU San Martino-IST, Genoa, Italy

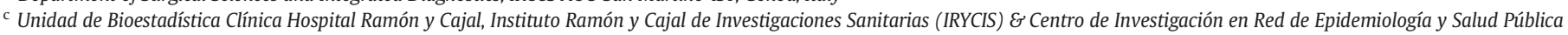
(CIBERESP), Spain

${ }^{\mathrm{d}}$ Division of Pulmonary and Critical Care Medicine, Faculty of Medicine, Ramathibodi Hospital, Mahidol University, Bangkok, Thailand

e Hospital Universitario de Montevideo, Uruguay

${ }^{\mathrm{f}}$ Alfred Hospital \& Monash University, Melbourne, Australia

${ }^{g}$ Hospital Nacional Alejandro Posadas, Buenos Aires, Argentina

${ }^{\mathrm{h}}$ Hospital HIGA Guemes, Haedo, Argentina

i Medizinische Hochschule Hannover, Germany

${ }^{\mathrm{j}}$ Hospital de Clínicas de Montevideo, Montevideo, Uruguay

k Clínica Medellín \& Universidad Pontificia Bolivariana, Medellín, Colombia

${ }^{1}$ Peking Union Medical College Hospital, Beijing, People's Republic of China

${ }^{m}$ Bombay Hospital Institute of Medical Sciences, Mumbai, India

"Policlinico “Agostino Gemelli”, Università Cattolica Del Sacro Cuore, Roma, Italy

- University Hospital of Poitiers, Poitiers, France

${ }^{\mathrm{p}}$ Hospital Universitario Sao Jose, Belo Horizonte, Brazil

${ }^{\mathrm{q}}$ Hospital Eugenio Espejo, Quito, Ecuador

${ }^{\mathrm{r}}$ Hospital Regional $1^{\circ}$ de Octubre, Instituto de Seguridad y Servicios Sociales de los Trabajadores del Estado (ISSSTE), México DF, México

${ }^{s}$ Medical Center Leeuwarden (MCL), Leeuwarden, The Netherlands

${ }^{\mathrm{t}}$ Asan Medical Center, University of Ulsan, Seoul, Republic of Korea

${ }^{u}$ Hospital de Sao José, Centro Hospitalar de Lisboa Central, Lisbon, Portugal

Hôpital Ibn Sina, Rabat, Morocco

w Papageorgiou Hospital, Thessaloniki, Greece

x South Texas Veterans Health Care System and University of Texas Health Science Center, San Antonio, TX, USA

${ }^{y}$ Interdepartmental Division of Critical Care Medicine, and Departments of Medicine \& Physiology, University of Toronto, Canada

\section{A R T I C L E I N F O}

\section{Keywords:}

Acute respiratory distress syndrome

Mechanical ventilation

Neurologic disease

Driving pressure

Neurologically critically ill patients

Pulmonary complications

\section{A B S T R A C T}

Purpose: In neurologically critically ill patients with mechanical ventilation (MV), the development of acute respiratory distress syndrome (ARDS) is a major contributor to morbidity and mortality, but the role of ventilatory management has been scarcely evaluated. We evaluate the association of tidal volume, level of PEEP and driving pressure with the development of ARDS in a population of patients with brain injury.

Materials and methods: We performed a secondary analysis of a prospective, observational study on mechanical ventilation.

Results: We included 986 patients mechanically ventilated due to an acute brain injury (hemorrhagic stroke, ischemic stroke or brain trauma). Incidence of ARDS in this cohort was 3\%. Multivariate analysis suggested that driving pressure could be associated with the development of ARDS (odds ratio for unit increment of driving

is Investigators of VENTILA group are showed in supplemental digital content.

* Corresponding author at: Intensive Care Unit, Hospital Universitario de Getafe, Carretera de Toledo, km 12.5, 28905 Getafe, Spain. E-mail address: evateje@gmail.com (E. Tejerina).

${ }^{1}$ Drs. Anzueto, Ferguson and Esteban contributed equally as senior authors. 
pressure 1.12; confidence interval for 95\%: 1.01 to 1.23) whereas we did not observe association for tidal volume (in ml per kg of predicted body weight) or level of PEEP. ARDS was associated with an increase in mortality, longer duration of mechanical ventilation, and longer ICU length of stay.

Conclusions: In a cohort of brain-injured patients the development of ARDS was not common. Driving pressure was associated with the development of this disease.

(c) 2016 Elsevier Inc. All rights reserved.

\section{Introduction}

Pulmonary complications such as pneumonia, atelectasis, acute lung injury (ALI), and acute respiratory distress syndrome (ARDS) are commonly seen in neurologically critically ill patients with mechanical ventilation. The development of ARDS is a major contributor to mortality, and it worsens long-term neurologic outcome [1,2]. A severely and globally altered initial brain computed tomography scan and low Glasgow Coma Scale have been reported as potential risk factors for the development of ARDS in patients with acute brain injury [1-3]. More recently, it has been proposed that therapeutic strategies such as a positive fluid balance, exposure to blood products, and vasopressor dependence [4] may contribute to the development of ARDS, among major underlying ARDS risk factors (aspiration, pneumonia and lung contusion) and the severity of injury $[3,5,6]$.

Conventional modalities of mechanical ventilation used in the management of patients with acute brain injury can often be in conflict with lung protective ventilation. Neurologically critically ill patients may be aggressively ventilated to optimize cerebral oxygenation and to maintain mild permissive hypocapnia for treatment of intracranial hypertension. This ventilatory strategy may further exacerbate the pulmonary and systemic inflammatory response and predispose to development of ARDS. Moreover, high volume ventilation has been identified as an independent predictor of early ARDS in patients with normal lungs admitted to a general intensive care unit $[7,8]$. Conversely, in recent systematic review and meta-analysis, ventilation with low tidal volumes has been associated with shorter duration of ventilation and lower risk of development of pulmonary complications in patients without acute respiratory distress syndrome [9,10].

However, clinical trials testing ventilation strategies designed for lung protection frequently excluded brain-injured patients, because of concerns about permissive hypercapnia while controlling intracranial pressure. As a result, different intracranial and extracranial independent predictors of ARDS have been previously identified in patients with neurological disorders, while the role of ventilatory management has been scarcely evaluated.

The objectives of the present study were to evaluate the incidence of ARDS and the effect of ventilatory settings on development of ARDS in a cohort of brain injured patients who required mechanical ventilation.

\section{Materials and methods}

\subsection{Design}

We analyzed data from a prospective, multicenter observational study of mechanically ventilated patients for at least $12 \mathrm{~h}$ admitted to 494 intensive care units (ICU) from 39 countries [11]. National coordinators recruited local investigators from eligible ICU. Only the investigator at each site was aware of the purpose and timing of the study in order to minimize practice changes in response to observation. The research ethics board of each participating institution approved the protocol and need for informed consent was according to local rules.

For the purpose of this analysis we included 986 patients mechanically ventilated due to an acute brain injury (hemorrhagic stroke, ischemic stroke, brain trauma).

\subsection{Protocol}

We collected baseline characteristics, daily ventilator settings, gas exchange, clinical management, and complication data while patients were ventilated or until day 28. Detailed descriptions of the variables collected and their definitions have been previously published [11]. Acute respiratory distress syndrome was defined according to the criteria from American European Consensus Conference (AECC) [12]: acute onset, ratio $\mathrm{PaO} 2$ to $\mathrm{FiO} 2<200$, bilateral infiltrate on chest radiograph and absence of heart failure. Those criteria must be met in two consecutive days to get a more consistent diagnosis.

\subsection{Statistical analysis}

Data are expressed as mean (standard deviation), median (interquartile range), absolute and relative frequencies as appropriate. We used Chi-square or Fisher's exact tests to compare categorical data between groups. We used the Kolmogorov-Smirnov test to assess continuous data for a normal distribution. We used two-tailed unpaired $t$-tests to compare normally distributed continuous data between two groups, and we used the Mann-Whitney $U$ test for non-normally distributed continuous data comparisons.

Because each patient had repeated measurements, a multivariate generalized estimation equations model to assess for an independent association between the tidal volume and ARDS was performed. The variables entered in the model were: severity at admission estimated

Table 1

Characteristics of patients included in the analysis.

\begin{tabular}{|c|c|c|c|}
\hline & $\begin{array}{l}\text { Hemorrhagic } \\
\text { stroke } \\
(N=470)\end{array}$ & $\begin{array}{l}\text { Ischemic } \\
\text { stroke } \\
(N=214)\end{array}$ & $\begin{array}{l}\text { Brain } \\
\text { trauma } \\
(N=302)\end{array}$ \\
\hline Age, years, mean (SD) & $61(14)$ & $65(14)$ & $46(20)$ \\
\hline Female, n (\%) & $207(44)$ & $70(33)$ & $77(25)$ \\
\hline Body mass index, $\mathrm{kg} / \mathrm{m}^{2}$, mean (SD) & $27(5)$ & $25(5)$ & $26(5)$ \\
\hline SAPS II, points, mean (SD) & $47(15)$ & $47(17)$ & $44(16)$ \\
\hline $\begin{array}{l}\text { Glasgow Coma Scale at admission, } \\
\text { points, mean (SD) }\end{array}$ & $6(3)$ & $7(3)$ & $6(3)$ \\
\hline \multicolumn{4}{|l|}{ Ventilator settings at day 0} \\
\hline \multicolumn{4}{|l|}{ Mode, n (\%) } \\
\hline Volume controlled $^{\mathrm{a}}$ & 307 (65) & $154(72)$ & $213(71)$ \\
\hline Pressure controlled $^{\mathrm{b}}$ & $145(31)$ & $55(26)$ & $80(26)$ \\
\hline Other ${ }^{\mathrm{c}}$ & $18(4)$ & $5(2)$ & $9(3)$ \\
\hline \multicolumn{4}{|l|}{ Tidal volume } \\
\hline In ml, mean (SD) & $517(88)$ & $507(97)$ & $512(89)$ \\
\hline In ml/kg ABW, mean (SD) & $7.1(1.6)$ & $6.9(1.5)$ & $7.2(1.6)$ \\
\hline In ml/kg PBW, mean (SD) & $8.4(1.6)$ & $8.2(1.5)$ & $8(1.4)$ \\
\hline PEEP, $\mathrm{cmH}_{2} \mathrm{O}$, mean (SD) & $5.2(1.9)$ & $5.4(2.2)$ & $5.5(1.9)$ \\
\hline \multicolumn{4}{|l|}{ Arterial blood gases at day 0} \\
\hline $\mathrm{pH}$, mean $(\mathrm{SD})$ & $7.39(0.09)$ & $7.36(0.12)$ & $7.34(0.11)$ \\
\hline $\mathrm{PaCO}_{2}, \mathrm{~mm} \mathrm{Hg}$, mean $(\mathrm{SD})$ & $39(11)$ & $43(18)$ & $38(10)$ \\
\hline Ratio $\mathrm{PaO}_{2}$ to $\mathrm{FiO}_{2}$, mean (SD) & $290(105)$ & $269(105)$ & $298(105)$ \\
\hline
\end{tabular}

a Includes controlled volume ventilation (CMV), and synchronized intermittent mandatory ventilation (SIMV).

b Includes pressure regulated volume controlled (PRVC), pressure controlled ventilation (PCV), pressure support (PS), airway pressure release ventilation/biphasic positive airway pressure (APRV/BIPAP).

c Includes continuous positive airway pressure (CPAP), Adaptive support ventilation (ASV), neural adjusted ventilatory assist (NAVA), proportional assist ventilation (PAV). 
by SAPS II, sepsis, shock, ventilator-associated pneumonia, tidal volume (expressed in $\mathrm{ml} / \mathrm{kg}$ of predicted body weight), applied PEEP and driving pressure. Analyses were performed using Stata 14.1.

\section{Results}

In Table 1 are showed the characteristics of patients included in the analysis.

\subsection{Incidence of ARDS}

Twenty-eight patients (3\%) met the criteria of ARDS over the course of mechanical ventilation. To meet the criteria, median time from intubation was 2 days (interquartile range 1-7). In Table 2 is showed the comparison of baseline, management variables and complications

Table 2

Comparison of patients with acute respiratory distress syndrome and patients without acute respiratory distress syndrome.

\begin{tabular}{|c|c|c|c|}
\hline & $\begin{array}{l}\text { ARDS } \\
(N=28)\end{array}$ & $\begin{array}{l}\text { No-ARDS } \\
(N=958)\end{array}$ & $P$ value \\
\hline Age, years, mean (SD) & 55 (19) & $58(18)$ & 0.418 \\
\hline Female, n (\%) & $9(32)$ & $345(36)$ & 0.674 \\
\hline Body mass index, $\mathrm{kg} / \mathrm{m}^{2}$, mean (SD) & $27(5)$ & $26(5)$ & 0.252 \\
\hline SAPS II, points, mean (SD) & $55(17)$ & $46(16)$ & 0.002 \\
\hline $\begin{array}{l}\text { Glasgow Coma Scale at admission, points, } \\
\text { mean (SD) }\end{array}$ & $6(2.5)$ & $6(3)$ & 0.689 \\
\hline \multicolumn{4}{|l|}{ Neurologic disease, $\mathrm{n}(\%)$} \\
\hline Hemorrhagic stroke & $12(43)$ & $458(48)$ & 0.605 \\
\hline Ischemic stroke & $5(18)$ & $209(22)$ & 0.616 \\
\hline Brain trauma & $11(39)$ & $291(30)$ & 0.313 \\
\hline \multicolumn{4}{|c|}{ Arterial blood gases on first day of mechanical ventilation } \\
\hline $\mathrm{pH}$, mean $(\mathrm{SD})$ & $7.32(0.08)$ & $7.37(0.11)$ & 0.166 \\
\hline $\mathrm{PaCO}_{2}, \mathrm{~mm} \mathrm{Hg}$, mean (SD) & $37(9)$ & $37(8)$ & 0.728 \\
\hline Ratio $\mathrm{PaO}_{2}$ to $\mathrm{FiO}_{2}$, mean (SD) & $221(117)$ & $285(104)$ & 0.002 \\
\hline \multicolumn{4}{|c|}{ Ventilator settings on the first day of mechanical ventilation } \\
\hline Mode, n (\%) & & & 0.461 \\
\hline Volume controlled ${ }^{\mathrm{a}}$ & $18(64)$ & $656(69)$ & \\
\hline Pressure controlled ${ }^{\mathrm{b}}$ & $10(36)$ & $270(28)$ & \\
\hline Other ${ }^{\mathrm{c}}$ & - & $32(3)$ & \\
\hline \multicolumn{4}{|l|}{ Tidal volume } \\
\hline In ml, mean (SD) & $512(70)$ & $513(91)$ & 0.932 \\
\hline In $\mathrm{ml} / \mathrm{kg}$ ABW, mean (SD) & $6.5(1.1)$ & $7.0(1.6)$ & 0.154 \\
\hline In $\mathrm{ml} / \mathrm{kg}$ PBW, mean (SD) & $8.0(1.2)$ & $8.2(1.7)$ & 0.511 \\
\hline PEEP, $\mathrm{cmH}_{2} \mathrm{O}$, mean $(\mathrm{SD})$ & $4.8(2.7)$ & $5.4(1.9)$ & 0.217 \\
\hline Driving pressure, $\mathrm{cmH}_{2} \mathrm{O}$, mean $(\mathrm{SD})^{\mathrm{d}}$ & $14(6)$ & $12(4)$ & 0.067 \\
\hline \multicolumn{4}{|l|}{ Variables related to management $\mathrm{e}^{\mathrm{e}}$} \\
\hline \multicolumn{4}{|l|}{ Tidal volume, ml/kg PBW, mean (SD) } \\
\hline Higher & $8.7(1.8)$ & $9.2(2.1)$ & 0.174 \\
\hline Lower & $7.5(1.8)$ & $7.3(1.6)$ & 0.608 \\
\hline \multicolumn{4}{|l|}{ PEEP, $\mathrm{cmH}_{2} \mathrm{O}$, mean (SD) } \\
\hline Higher & $8.5(4.3)$ & $6.7(2.8)$ & 0.001 \\
\hline Lower & $5.2(3.2)$ & $4.7(1.9)$ & 0.244 \\
\hline Higher driving pressure, $\mathrm{cmH}_{2} \mathrm{O}$, mean (SD) & $19(5)$ & $14(4)$ & $<0.001$ \\
\hline Lower ratio $\mathrm{PaO}_{2}$ to $\mathrm{FiO}_{2}$, mean (SD) & $99(34)$ & $210(90)$ & $<0.001$ \\
\hline Higher $\mathrm{PaCO}_{2}, \mathrm{~mm} \mathrm{Hg}$, mean (SD) & $46(11)$ & $43(10)$ & 0.161 \\
\hline Steroids, $\mathrm{n}(\%)$ & $2(7)$ & $135(14)$ & 0.295 \\
\hline $\begin{array}{l}\text { Cumulative fluid balance, ml, median } \\
\text { (interquartile range) }\end{array}$ & $\begin{array}{l}837(-700 \\
3335)\end{array}$ & $\begin{array}{l}2698 \\
(230,6592)\end{array}$ & 0.087 \\
\hline \multicolumn{4}{|c|}{ Events over the course of mechanical ventilation ${ }^{\mathrm{e}}$} \\
\hline Sepsis, $\mathrm{n}(\%)$ & $14(50)$ & $138(14)$ & $<0.001$ \\
\hline Ventilator associated-pneumonia, n (\%) & $5(18)$ & $53(5.5)$ & 0.006 \\
\hline Shock, n (\%) & $23(82)$ & $429(45)$ & $<0.001$ \\
\hline
\end{tabular}

Abbreviations: ARDS: acute respiratory distress syndrome; PEEP: positive end-expiratory pressure; SD: standard deviation.

a Includes controlled volume ventilation (CMV), and synchronized intermittent mandatory ventilation (SIMV).

$\mathrm{b}$ Includes pressure regulated volume controlled (PRVC), pressure controlled ventilation (PCV), pressure support (PS), airway pressure release ventilation/biphasic positive airway pressure (APRV/BIPAP).

c Includes continuous positive airway pressure (CPAP), Adaptive support ventilation (ASV), neural adjusted ventilatory assist (NAVA), proportional assist ventilation (PAV).

d Driving pressure $=$ plateau pressure minus PEEP. Data missing in 353 patients (15 in cohort of patients with ARDS and 338 in cohort of patients without ARDS).

e In patients with ARDS, the data are corresponding to register before diagnosis of ARDS.
Table 3

Outcome according to diagnosis of acute respiratory distress syndrome.

\begin{tabular}{lllc}
\hline & $\begin{array}{l}\text { ARDS } \\
(N=28)\end{array}$ & $\begin{array}{l}\text { No-ARDS } \\
(N=958)\end{array}$ & P value \\
\hline $\begin{array}{l}\text { Days of ventilatory support, median } \\
\text { (interquartile range) }\end{array}$ & $12(5,24)$ & $7(4,13)$ & 0.016 \\
$\begin{array}{l}\text { Length of stay in the intensive care unit, } \\
\text { median (interquartile range) }\end{array}$ & $12(5,34)$ & $8(4,18)$ & 0.063 \\
$\begin{array}{l}\text { Length of stay in hospital, median } \\
\quad \text { interquartile range) }\end{array}$ & $15(6,30)$ & $13(6,56)$ & 0.510 \\
$\begin{array}{l}\text { Mortality in the intensive care unit, n (\%) } \\
\text { Mortality at day 28, n (\%) }\end{array}$ & $18(64)$ & $357(37)$ & 0.004 \\
$\quad$ Mortality in the hospital, n (\%) & $15(53)$ & $392(41)$ & 0.180 \\
\hline
\end{tabular}

a Missing data in 53 patients.

between patients who were diagnosed of ARDS and patients without the criteria of ARDS.

Comparison in the outcome of both groups is showed in Table 3.

\subsection{Effect of tidal volume, applied PEEP and driving pressure on} development of ARDS

After adjustment for severity at admission (estimated by SAPS II), known risk factors for ARDS (sepsis, shock, ventilator associated pneumonia) and variables related to ventilatory management (tidal volume, applied positive end-expiratory pressure and driving pressure) only driving pressure was associated with the diagnosis of ARDS: odds ratio per unit of increase of driving pressure 1.12; confidence interval for 95\%: 1.01 to 1.23 .

\section{Discussion}

In this prospective observational study of mechanically ventilated patients with critical neurologic illness, we found that: 1) ARDS is not a common event; 2 ) a high driving pressure was associated to a higher risk for ARDS; 3) ARDS was associated with a twofold increase in mortality, longer duration of mechanical ventilation, and longer ICU length of stay.

The incidence of ARDS in this cohort was lower than has been reported in other studies of brain-injured patients. In previous reports, ARDS occurs in up to $20-38 \%$ of cases of subarachnoid haemorrhage [13-15], traumatic brain injury $[1,16]$ and spontaneous intracerebral haemorrhage $[4,5,17,18]$, and $35 \%$ reported in a mixed cohort of neurologically ill patients [19]. Variability in ARDS incidence may reflect differences in study populations and in diagnosis approach, variable use of consensus approach. In our study, diagnostic criteria for ARDS must be met in two consecutive days to get a more consistent diagnosis. This is supported by recent reports [20,21]. In an observational study, the use of a standardized ventilatory setting at $24 \mathrm{~h}$ of ARDS onset allowed a more precise and clinically relevant stratification of ARDS patients [20]. And, in other large, observational study demonstrated that risk stratification of ARDS patients based on $\mathrm{PaO} 2 / \mathrm{FiO} 2$ recorded at ARDS onset (baseline) is not clinically useful [21].

Currently, little is known about the etiology of ARDS in neurologically critically ill patients. Literature describes a "double hit model", postulating that injurious strategies of mechanical ventilation can act as a second hit on lungs already preconditioned by the catecholamine storm and the systemic production of inflammatory mediators following brain injury [6,7]. In this context, high volume ventilation may further exacerbate the pulmonary and systemic inflammatory response in brain-injured patients with ALI/ARDS, and hyperventilation for permissive hypocapnia may be associated with more lung injury [22]. In a large-scale observational study, it was noted that neurologic patients were ventilated with mean tidal volumes approximating a $9 \mathrm{ml} / \mathrm{kg}$ of predicted body weight [23]. Higher tidal volume has also been identified as a significant and modifiable risk factor for the development of 
ARDS in patients with neurological disorders [4,5]. In fact, high tidal volume ventilation has been associated to ventilator-induced lung injury (VILI) related to overdistention during mechanical ventilation (volutrauma), recruitment-derecruitment of collapsed alveoli (atelectrauma), and activation of inflammatory processes (biotrauma) $[6,22,24]$. So, in general ICU patients, the goals of mechanical ventilation have changed over the past 10 years from maintaining normal blood gas values, to maintaining adequate gas exchange while attempting to minimize VILI [25]. And, to minimize VILI most studies have scaled $V_{T}$ to predicted body weight to normalize $V_{T}$ to lung size. However, many studies suggest that tissue damage is more closely related to the unphysiological lung strain and stress generated by mechanical ventilation with large tidal volume. Thus, driving pressure is the surrogate for cycling lung strain that is most accessible and easiest to calculate, and cyclic strain predicts lung injury better than $\mathrm{V}_{\mathrm{T}}$. Accordingly, normalizing $\mathrm{V}_{\mathrm{T}}$ to respiratory-system compliance would provide a better predictor of VILI than $\mathrm{V}_{\mathrm{T}}$ alone [26]. Furthermore, a recent study also suggests that, among the respiratory variables monitored at the bedside, driving pressure was the strongest predictor of mortality [27]. So, the finding that the driving pressure is independently associated with the development of ARDS, implies that patients in whom a change in ventilator settings reduces driving pressure may have better outcome. A previous analysis $[27,28]$ did not include neurologically critically ill patients. Thus, our results extend knowledge about protective ventilation and the potential role of the driving pressure in this population, given that brain injury may act as a preconditioning factor rendering the lung more susceptible to subsequent lung damage induced by mechanical ventilation [29].

Other therapeutic strategies, aside from ventilatory settings, could contribute to the development of ARDS in neurocritical patients. Several studies have shown ARDS to be a consequence of underlying illness and predisposing conditions such as young age, male gender, ethnicity, history of chronic arterial hypertension, diabetes, chronic obstructive pulmonary disease, development of sepsis, cardiovascular, renal and haematological dysfunctions [17,30,31]. In addition, other interventions such as exposure to blood products may potentiate pulmonary injury in a susceptible host or lead directly to transfusion-related ARDS. And, induced hypertension, frequently required for the management of cerebral perfusion pressure in patients with elevated intracranial pressure, has also been associated with an increased incidence of ARDS [3].

Among the extracranial factors, administration of vasoactive drugs and history of drug abuse have also been identified as independent predictors of ARDS in patients with traumatic brain injury [3]. However, our data suggest that the development of ARDS in neurologically mechanically ventilated patients is specifically associated with high driving pressure.

In our study, ARDS patients developed more complications during mechanical ventilation such as shock, sepsis and pneumonia associated with ventilation. ARDS was also associated with a significant increase in mortality, and it prolonged the duration of mechanical ventilation and the length of ICU stay. Similarly, in previous reports, ARDS has been identified as a major contributor to the morbidity and mortality of patients with brain injuries $[2,3,5,15,17,18,30]$. ARDS also worsens longterm neurologic outcome $[1,2,3,32]$, and is associated with longer ICU and hospital length of stay $[5,29]$. Conversely, other studies $[4,5,33]$ did not observe a direct association between ARDS and mortality, and the authors argued that this result may be explained by the fact that in patients with severe brain injury, the effect of ARDS is obscured by the overall mortality driven by the severity of the brain injury rather than other organ failures.

Our study has several limitations. First, this was a post-hoc analysis of previously and prospectively collected clinical data from a wide variety of ICUs, patient conditions, and clinical practices. Second, we used the traditional AECC definition of ARDS [12] as we could not apply the more recent Berlin definition [34] because the studied cohorts were prior to the Berlin conference. Otherwise, both definitions have serious limitations [20]. As the Berlin criteria, similar to the AECC criteria, did not mandate the assessment of hypoxemia under standardized ventilatory conditions, the values of $\mathrm{PaO} 2 / \mathrm{FiO} 2$ recorded at the time of ARDS diagnosis do not provide accurate assessment of ARDS severity and outcome [21]. Even for patients with severe ARDS by the Berlin definition, only $58 \%$ demonstrated diffuse alveolar damage on autopsy [35]. Hence, one can consider that the Berlin definition also lacks specificity, and the recent LungSafe survey showed that ARDS is frequently underdiagnosed by clinicians [36]. Third, information about some important ARDS risk factors, such as massive transfusion and drug overdose was not collected as part of an international study increasing the chance for residual confounding by unmeasured variables. Fourth, we have not collected treatment variables of intracranial hypertension or specific monitoring data (intracranial pressure, cerebral perfusion pressure, etc.), but we assume that neurological patients have been treated according to the protocols and guidelines published. Fifth, we have entered the driving pressure in our analysis despite the fact that this variable has missing data (usually plateau pressure was not registered in patients ventilated with pressure controlled modes). Additionally, we were not able to collect systemic data on left ventricular filling pressures, so we determined the presence or absence of left atrial hypertension based on other available data and may have misclassified some cases of cardiogenic pulmonary edema as ARDS. Finally, this study focused on general outcomes and the details related to mechanical ventilation, thus we did not examine neurologic outcome.

In summary, the results of this study indicate that the incidence of ARDS in a mixed cohort of neurologically mechanically ventilated patients is low, and the development of ARDS is associated with the effect of a high driving pressure, a potentially modifiable risk factor. Furthermore, ARDS has a great impact on morbidity and mortality in patients suffering from brain injury and is associated with longer duration of mechanical ventilation, and longer ICU length of stay.

\section{Appendix A. Supplementary data}

Supplementary data to this article can be found online at http://dx. doi.org/10.1016/j.jcrc.2016.11.010.

\section{References}

[1] Holland MC, Mackersie RC, Morabito D, et al. The development of acute lung injury is associated with worse neurologic outcome in patients with severe traumatic brain injury. J Trauma 2003;55:106-11.

[2] Bratton SL, Davis RL. Acute lung injury in isolated traumatic brain. Neurosurgery 1997:40:707-12.

[3] Contant CF, Valadka AB, Gopinath SP, Hannay HJ, Robertson CS. Adult respiratory distress syndrome: a complication of induced hypertension after severe head injury. J Neurosurg 2001;95:560-8.

[4] Elmer J, Hou P, Wilcox SR, et al. Acute respiratory distress syndrome after spontaneous intracerebral hemorrhage. Crit Care Med 2013;41:1992-2001.

[5] Mascia L, Zavala E, Bosma K, et al. High tidal volume is associated with the development of acute lung injury after severe brain injury: an international observational study. Crit Care Med 2007;35:1815-20.

[6] Mascia L. Acute lung injury in patients with severe brain injury: a double hit model Neurocrit Care 2009;11:417-26.

[7] Gajic O, Frutos-Vivar F, Esteban A, Hubmayr RD, Anzueto A. Ventilator settings as a risk factor for acute respiratory distress síndrome in mechanically ventilated patients. Intensive Care Med 2005;31:922-6.

[8] Gajic O, Dara SI, Mendez JL, et al. Ventilator-associated lung injury in patients without acute lung injury at the onset of mechanical ventilation. Crit Care Med 2004;32:1817-24.

[9] Serpa Neto A, Simonis FD, Barbas CSV, et al. Association between tidal volume size duration of ventilation, and sedation needs in patients without acute respiratory distress syndrome: an individual patient data meta-analysis. Intensive Care Med 2014; 40:950-7.

[10] Serpa Neto A, Simonis FD, Barbas CSV, et al. Lung-protective ventilation with low tidal volumes and the occurrence of pulmonary complications in patients without acute respiratory distress syndrome: a systematic review and individual patient data analysis. Crit Care Med 2015;43:2155-63.

[11] Esteban A, Frutos-Vivar F, Muriel A, et al. Evolution of mortality over time in patients receiving mechanical ventilation. Am J Respir Crit Care Med 2013;188:220-30.

[12] Bernard GR, Artigas A, Brigham KL, et al. The Consensus Committee. The AmericanEuropean Consensus Conference on ARDS. Definitions, mechanisms, relevant outcomes, and clinical trial coordination. Am J Respir Crit Care 1994;149:818-24. 
[13] Wartenberg KE, Schmidt JM, Claassen J, et al. Impact of medical complications on outcome after subarachnoid hemorrhage. Crit Care Med 2006;34:617-23.

[14] Veeravagu A, Chen YR, Ludwig C, et al. Acute lung injury in patients with subarachnoid hemorrhage: a nationwide inpatient sample study. World Neurosurg 2014;82: e235-41.

[15] Kahn JM, Caldwell EC, Deem S, et al. Acute lung injury in patients with subarachnoid hemorrhage: incidence, risk factors, and outcome. Crit Care Med 2006;34:196-202

[16] Rincon F, Ghosh S, Dey S, et al. Impact of acute lung injury and acute respiratory distress syndrome after traumatic brain injury in the United States. Neurosurgery 2012; 71:795-803.

[17] Naidech AM, Bassin SL, Garg RK, et al. Cardiac troponin I and acute lung injury after subarachnoid hemorrhage. Neurocrit Care 2009;11:177-82.

[18] Kitamura Y, Nomura M, Shima H, et al. Acute lung injury associated with systemic inflammatory response syndrome following subarachnoid hemorrhage: a survey by the Shonan Neurosurgical Association. Neurol Med Chir (Tokyo) 2010;50: 456-60.

[19] Hoesch RE, Lin E, Young M, et al. Acute lung injury in critical neurological illness. Crit Care Med 2012;40:587-93.

[20] Villar J, Pérez-Méndez L, Blanco J, et al. A universal definition of ARDS: the PaO2/FiO2 ratio under a standard ventilator setting: a prospective, multicenter, validation study. Intensive Care Med 2013;39:583-92.

[21] Villar J, Blanco J, del Campo R, et al. Assessment of PaO2/FiO2 for stratification of patients with moderate and severe acute respiratory distress syndrome. BMJ Open 2015;5, e006812.

[22] Neumann JO, Chambers IR, Citerio G, et al, Group BIT. The use of hyperventilation therapy after traumatic brain injury in Europe: an analysis of the BrainIT database. Intensive Care Med 2008;34:1676-82.

[23] Pelosi P, Ferguson ND, Frutos-Vivar F, et al. For the Ventila Study Group Management and outcome of mechanically ventilated neurologic patients. Crit Care Med 2011;39: $1482-92$.

[24] Brower RG, Matthay MA, Morris A, et al. The acute respiratory distress syndrome network. Ventilation with lower tidal volumes as compared with traditional tida volumes for acute lung injury and the acute respiratory distress syndrome. $\mathrm{N}$ Engl J Med 2000;342:1301-8.
[25] Esteban A, Ferguson ND, Meade MO, et al. Evolution of mechanical ventilation in response to clinical research. Am J Respir Crit Care Med 2008;177:170-7.

[26] Protti A, Andreis DT, Monti M, et al. Lung stress and strain during mechanical ventilation: any difference between statics and dynamics? Crit Care Med 2013;41: 1046-55.

[27] Amato MB, Meade MO, Slutsky AS, et al. Driving pressure and survival in the acute respiratory distress syndrome. N Engl J Med 2015;372:747-55.

[28] Serpa Neto A. Hemmes SN, Barbas CS, et al Association between driving pressure and development of postoperative pulmonary complications in patients undergoing mechanical ventilation for general anaesthesia: a meta-analysis of individual patient data. Lancet Respir Med 2016;4:272-80.

[29] Oddo M, Citerio G. ARDS in the brain-injured patient: what's different? Intensive Care Med 2016;42:790-3.

[30] Rincon F, Maltenfort M, Dey S, et al. The prevalence and impact of mortality of the acute respiratory distress syndrome on admissions of patients with ischemic stroke in the United States. J Intensive Care Med 2014;29:357-64.

[31] Ghosh S, Dey SK, Maltenfort M, et al. Epidemiological trends of adult respiratory distress syndrome (ARDS) after traumatic brain injury in the United States. New Orleans, La, USA: American Academy of Neurology; 2012.

[32] Gruber A, Reinprecht AU, Illievich M, et al. Extracerebral organ dysfunction and neurologic outcome after aneurismal subarachnoid hemorrhage. Crit Care Med 1999;27: 505-14.

[33] Treggiari MM, Hudson LD, Martin DP, Weiss NS, Caldwell E, Rubenfeld G. Effect of acute lung injury and acute respiratory distress syndrome on outcome in critically ill trauma patients. Crit Care Med 2004;32:327-31.

[34] Definition Task Force ARDS, Ranieri VM, Rubenfeld GD, Thompson BT, et al. Acute respiratory distress syndrome: the Berlin definition. JAMA 2012;307:2526-33.

[35] Thille AW, Esteban A, Fernandez-Segoviano P, et al. Comparison of the Berlin definition for acute respiratory distress syndrome with autopsy. Am J Respir Crit Care Med 2013;187:761-7.

[36] Bellani G, Laffey JG, Pham T, et al, Investigators LUNGSAFE, Trials Group ESICM. Epidemiology, patterns of care, and mortality for patients with acute respiratory distress syndrome in intensive care units in 50 countries. JAMA 2016;315:788-800. 